\title{
APPLICATION OF SAFETY PROGRAM ELEMENT TO RISK MANAGEMENT ANALYSIS IN CONSTRUCTION
}

\author{
Onyeka, F.C. \\ Department of Civil Engineering, Edo University, Iyamho, Nigeria. \\ Agunwamba, J.C. \\ Department of Civil Engineering, University of Nigeria, Nsukka, Nigeria.
}

\begin{abstract}
With the rapid development of economic and technology in Nigeria, structural forms are becoming more and more complicated, which requires more rigorous construction technology and construction management. However, the risk management in our country is still in its infancy, and managers are short of awareness of risks and lack of ability to manage risks. Despite recent efforts to improve site safety, construction still accounts for a disproportionate number of occupationalrelated fatalities. Study on risk management methods mode of conventional construction process shows that only relying on the qualitative analysis by perfecting manage system and engineering experience cannot satisfy the construction requirement of the complicated structures. This study used quantitative method to assess risk and then develop strategies to manage it. It is such that risks with the greatest loss and the greatest probability of occurring are handled first, and risks with lower probability of occurrence and lower loss are handled in descending order; though in practice the process can be very difficult. This paper applied this method of risk management to Agbani, Rangers Avenue, Desala and Mkpokiti road constructed by ARAB contractors in Enugu State. This was done by using safety equilibrium model to compare results of the four projects with respect to application / ability of these safety program elements to the construction project. Twelve, fourteen, fifteen and seventeen safety program elements were applied in Agbani, Rangers Avenue, Desala and Mkpokiti and and safety risk demand obtained were 112.3 work-hours per incident per injury, 105.2 work-hours per incident per injury,101.4 work-hours per incident per injury, and 126.4 work-hours per incident per injury respectively. Results of the analysis shows that safety risk capacity obtained at the four sites were 93.23 work-hours per incident per injury, 110 work-hours per incident per injury, 123.2 work-hours per incident per injury, and 132 work-hours per incident per injury respectively. This implies that applying a higher number of safety program elements will improve site safety and consequently reduce construction risks. It is concluded that most of the risk prevalent problem in construction industry which led to casualties and fatalities are preventable if the risks in the construction are well known at the earlier stage of construction.
\end{abstract}


Keywords: Construction, Risk Management, Safety, Safety Program Elements.

Cite this Article: Onyeka, F.C. and Agunwamba, J.C., Application of Safety Program Element to Risk Management Analysis in Construction, International Journal of Advanced Research in Engineering and Technology, 10 (5), 2019, pp 38-48. http://iaeme.com/Home/issue/IJARET?Volume=10\&Issue $=5$

\section{INTRODUCTION}

Every activity in human endeavor is incumbent with its own risk or risks inimical to identify, analyze and mitigate such risk or risks cannot be over-emphasized. Risks are uncertainties, liabilities, or vulnerabilities, which may cause a project to deviate from its defined plan. While risk in a project environment cannot be totally eliminated or transferred, it can be monitored and minimized or mitigated wherever possible. To succeed, organizations must commit to addressing risk management throughout the project lifecycle (Alvarez et al, 2002).

Risk is uncertainty of outcome, whether positive opportunity or negative threat, of actions and events. Risk and uncertainty characterize situations where the actual outcome for a particular event or activity is likely to deviate from the estimated or forecast value (Raftery, 1994). ). Risk can travel in two directions: the outcome may be better or worse than originally expected. These are known as upside and downside risks.

The distinction between risk and uncertainty is usually that risk is taken to have quantifiable attributes, insurable, and it was possible to make a statistical assessment of the probability of occurrence of a particular event, whereas uncertainty does not. Risks and uncertainties can cause losses, which lead to increasing costs and time delays, both during the project and at the end. It requires more rigorous construction technology and construction management.

Some years ago risk management was theoretical concept seldom used in the construction industry. In recent times, it is referred to as one of the most fundamental components of construction best practice and widely recommended as essential activity in the research. However, the risk management in our country is still in its infancy, and managers are short of awareness to risks and lack of ability to manage it. Owners, contractors, construction managers, designers and others have a number of options to protect themselves from the hazards of business. Barrie and Paulson (1992) defined risk management as an organized approach to identifying and dealing with potential exposures. The risk has to be assessed in respect of the combination of the likelihood of something happening, and the impact which arises if it does actually happen. Risk management includes the identification and assessment of risks together with the development of strategies to minimize them and with the development when they do occur, to mitigate any adverse effects or take advantage of beneficial ones (Lockyer and Gordon, 1996). It involves the systematic application of management policies and tools to analyze and assess potential impacts of uncertain future events, such as fires, explosions, toxic releases and natural events.

Thus, proactive risk assessment and sound risk management is necessary to protect an organization's competitive position. The construction industry, more than most industries, is particularly plagued by risk, but it has been slow in realizing the potential benefits of sound and systematic risk management (Al-Bahar and Crandall, 1990; Ward et. al. 1991; Thomson and Perry, 1992; Flanagan and Norman, 1993; Raftery, 1994; Fellows, 1996; Edward and Bowen, 1998). Risk analysis and risk management had their origins in the insurance industry in the USA in the 1940s. Using this logic, the actual risk to be carried was quantified as follows: 
In view of the foregoing, risk management is expected to commence with project inception through the planning stage to the construction and quality control stage. In other words risk management should be the integral part of cost planning and control of road construction project. In Nigeria today, risk management as an integral part of project management is yet to attain the level of unequivocality it deserves in the process of assuring quality, coupled with time and cost effectiveness, the construction industry is supposed to provide for the effort being put into construction projects. Barrie and Paulson (1992) opined that risk management in the construction industry includes an organized effort to indentify and quantitatively evaluate explosives along with an advance plan designed to eliminate or mitigate the consequences of the risks.

Construction projects have a bad reputation of failing to meet the deadlines and cost targets. That's why identifying risk sources is extremely important, since it is not necessarily possible to identify single risks. Odeh and Battaineh studied the most typical reason for construction delays: owner interference, inadequate contractor experience, financing and payments, labor productivity, slow decision making, improper planning and sub-contractors. Authors emphasized the meaning of experience and capability of project participants to have the most effect on these causes of delays. These kinds of risks can be seen as network-related. Thus in order to have a successful project, it should be guaranteed by some means that all participants are experienced and trained to do the project: it matters what kind of network is conducting the work. To improve the present situation, authors suggest different kinds of improvements to the contracts, incentives for good quality and awarding capabilities more than just the price.

Safety program is a very crucial element applied in safety risk mitigation. In addition to greatly reducing the chances of having an accident or incident in the first place, a good safety program will lead directly to higher employee morale, performance and profitability. If maintained over a period of time, it can lead to more positive benefits, such as lower employees' compensation and liability insurance rates for your company, greater participation and support from our supplier community as industry professionalism increases, and the attraction of a larger pool of qualified people into our industry. This research provides the industry with some confirmation that safety programs are, indeed, effective. In order to understand the implications of the proposed model, one must fully understand the current safety management practices that dominate the industry.

In a nut-shell, the Nigeria construction industry is still lacking in the area of proper risk identification and management, the alleviation of which this research work is being focused especially at cost planning, risk mitigation strategy and control stage of road projects with a special reference to how the safety officer, and risk manager function in these aspect of construction work.

\subsection{Risks in Construction Project}

According to Flanagan and Norman (1993) the construction industry is subject to more risks than other industries. In construction projects, risks and uncertainties are of several types (Abdou et al, 2004). Checklist of risks in construction project according to Perry and Hayes (1985) include:

(a) Physical risk: Force Majeure (act of God) earthquake, flood, landslide etc. pestilence, disease.

(b) Construction risk: Delay in possession of site, productivity of equipment, quality, availability and productivity of labour; new technology or methods- application and feasibility; failure to construct a programmed and specification; poor workmanship, damage 
during transportation or storages. Delay of information from designers, damage during construction due to negligence of any party, vandalism and accident etc.

(c) Design risk: Incomplete design scope, availability of information, innovation application, new technology, level of detail required and accuracy, appropriateness of specification, likelihood of change, interaction of design with method of construction, nonstandard detail etc.

(d) Political risk: Change in law, war, revolution, civil disorder; constrains on the availability of labour, customs and export restrictions and procedures; requirement to joint venture with local organization; inconsistency of regulations within the country or organization; embargo etc.

(e) Financial risk: Availability of funds of client cash flow of client particularly effect of delay, loss due to default of contractor, subcontractor, supplier or clients; cash flow problems for contractor due to slow payment by clients of completed works, disputes, inflation, inadequate payment variation, insufficient insurance, exchange rate fluctuation etc.

(f) Legal-contractual risk: Direct liability, liability to other local laws and codes, condition of contract liquidated damages, maintenance, hold-harmless clauses.

(g) Environment risk: ecological damage, pollution, waste treatment, preserving historical finds, local environment regulations etc.

\subsection{Safety Program Element in Construction}

This is a general plan element in the construction project seeks by the safety officer aimed at reducing potential risk, death, injuries, damage to property, and economic and social dislocation that could result from safety hazards to new development by proper planning and to minimize existing risk through coordinated City-County actions.

A complete safety program will include:

(1) The written programs describing how you train your employees and set up a safe working environment for the kinds of tasks and activities your employees perform,

(2) A systematic method for documenting your safety compliance activities and compliance of your employees with company safety policies and procedures, and

(3) The necessary investment in the equipment and tools, including appropriate personal protective equipment, needed for a safe working environment. In addition to greatly reducing the chances of having an accident or incident in the first place, a good safety program will lead directly to higher employee morale, performance and profitability.

\subsection{Risk Management Systems}

Risk management is a discovery of existing risk, by observation and imagination, the estimation of the probability and seriousness of these potential impacts and the consideration of methods of mitigating these risks and the implementation and evaluation of the decisions made (Okwuoma, 2009). Risk management includes the identification and assessment of risks together with the development of strategies to minimize them and with the development when they do occur, to mitigate any adverse effects or take advantage of beneficial ones (Lockyer and Gordon, 1996).

Risk management systems are used in companies and organizations to ensure the control of risks in the business or construction process. In this thesis the simplest possible approach to describe the risk management process is chosen due to the context of the construction sector (Okolie, 2005). 
One study combines construction safety risk identification with mitigation techniques. Jannadi and Almishari (2003) introduce The Risk Assessor, a knowledge-management program, which quantifies risk using the common risk formula below:

$$
\text { Activity Risk Score }=(\text { Severity }) \mathbf{x}(\text { Exposure }) \mathbf{x} \text { (Probability) }
$$

Risk management process consists of the risk analysis followed by the risk response. Risk analysis refers to the inclusion of identification and assessment.

\subsubsection{Risk Identification}

This is a risk management procedure because the most troublesome tools of risk manager are the problem of identifying the various hazards and risk confronting his firm. Risk identification is a diagnostic process in which all the potential tasks that could affect a construction are identified and investigated, thus enabling the client to understand the potential risk sources at an early stage in the project. In order to manage risk, an organization needs to know what risk $s$ that it faces, and to evaluate them. Identifying risk is the first step in building the organization's risk profile. There is no single right way to document an organization's risk profile, but the documentation is crucial to effective management of risk (Treasury, 2004).

\subsubsection{Risk Assessment/Analysis}

Risk analysis or assessment is a complex stage, regardless of the activity associated with it, because, beyond any statically and mathematical calculations, implies a certain vision and an attempt to predict the future, to assess possible dangers, attacks and threat which could face an economic entity including the actions involved in its activities. In principle, risks assessment or analysis is a systematic process in identifying and comparing them or considering the organization's key assets, threats and vulnerabilities that can occur, the likelihood and consequences and protective measures that can be counteracted (Simu, 2006).

Risk Analysis is used to evaluate risks quantitatively, and to ascertain the importance of each risk to the project base on the assessment of the probability of its occurrence. Risk analysis assesses both the effects of individual risks and the combined consequences of all the risks on the project objectives. There are two primary methods of risk analysis and one hybrid method (Meritt, 2008), and they are Qualitative risk analysis and Quantitative risk analysis.

\subsubsection{Risk Response}

And retention. Risk management processes involve the formulation of management response to the risks using the information collected during the risk analysis phase. A risk response should be decided after a risk's possible causes and effects have been considered fully understood. It will take the form of one or more of the following management actions. Response, which is initiated within the organization, to risk is called "internal control" and may involve Risk Reduction, Risk Transfer, Risk Allocation, Risk Avoidance, Mitigation of Risk, and Risk Retention/Acceptance.

\subsection{Modelling of Risk}

Modeling consists of finding appropriate probability distributions for all uncertainty factors, which may affect the consequences of decision. The modeling is the first step in decision making under uncertainty and is very crucial step (Pflug and Romisch, 2007).

Modeling involves identifying and selecting relevant features of real-world situation, representing those features symbolically, analyzing and reasoning about the model and characteristics of the situation, and considering the accuracy and limitations of the model.

The main purpose of modeling risks/uncertainty in construction cost estimating and forecasting is to reflect the effect of associated uncertainty in the cost of estimating process to 
have more realistic estimate. It will present a clearer vision with more information to the decision making process from both client's and the constructor's side (Abdou et al, 2004).

\subsubsection{Safety Risk Management Model}

In order to apply this concept of safety management model as presented in the safety equilibrium equation $(\mathrm{Su}<\Phi \mathrm{Sn})$, one must identify and define both the safety risk demand and the capacity of the safety program. Once the safety risk demand has been quantified, the equilibrium equation above may be applied. By using the concept of equilibrium and the quantified risk mitigation capacity of each safety program element, one may define the relative effectiveness of safety program elements and identify when equilibrium between safety risk demand and the capacity of the safety program has been achieved.

\section{METHODOLOGY}

The approach of methodology adopted for this study is to observe activities of road construction project execution in Agbani, Rangers Avenue, Desala and Mkpokiti construction site operated by ARAB contracting firm Enugu branch. The target audience includes construction professionals having to do with contractor selection and construction management in the construction industry e.g. Engineers, Quantity surveyors and, skilled operatives like tillers, concreters, carpenters etc.

The design of this study was analytical/technique design. This research design was chosen because the study carefully involves data collection from construction industry participants to analyze the risk involve in the road construction project.

\subsection{Method of Data Analysis}

Quantitative method of risk analysis was used in this work. The researcher used a model produced (Hallowell and Gambatese, 2007) in Georgia Tech, Atlanta USA, which describe a formal method of construction safety management and was called Safety risk management model equilibrium. This was used to analyze and evaluate risk result for both data obtained from the project manager and the one gotten from experts on safety and risk management (i.e. risk manager, and safety officer) in the four sites. This model was derived from the concept of equilibrium based on Newton's third law using the illustration in the design relationship for flexure in a structural member:

$$
\mathrm{Mu}<\Phi \mathrm{Mn}
$$

Where,

$\mathrm{Mu}$ : Ultimate Moment (i.e., maximum design or demand),

Mn: Design Moment (i.e., nominal moment or capacity),

$\Phi:$ Factor of Safety

When this same concept is applied in construction safety one may recognize that the safety risk demand is equal to the sum of the safety risk on a construction site. Assuming that every safety program element offers some form of safety risk mitigation, the sum of that mitigation ability is equal to the capacity of the safety system. In theory, to reach equilibrium and make the system stable (i.e. accident free), the capacity of the safety program must meet or exceed the safety demand. This relationship is expressed in the following (Equation 2.2) modeled after equation 2.1 .

$$
\mathrm{Su}<\Phi \mathrm{Sn}
$$

Where,

Su: Safety Risk Demand (i.e. the cumulative safety risk on the construction site) 
Sn: Safety Capacity (i.e. the cumulative mitigation ability of the safety program)

$\Phi:$ Factor of Safety

Once a road safety issue has been identified, risk is assessed and quantified to the public as information to be used by the decision makers. The quantification of risk involves the estimation of the likelihood (probability) of an unintentional release of stored or useful resources.

This relationship is expressed in the following equation, modeled after Yi and Langford (2006):

Risk value $(\mathrm{Ri})=$ probability $(\mathrm{p}) \times$ severity $(\mathrm{s})$. This implies that;

$$
\mathrm{Ri}=\mathrm{p} \times \mathrm{s}
$$

Also; Risk mitigation $(\mathrm{Rj})=$ probability reduction $(\mathrm{ps}) \mathrm{x}$ severity reduction $(\mathrm{sr})$. This implies that;

$$
R j=p s x s
$$

\section{RESULTS AND DISCUSSION}

A panel of 18 construction safety experts was created and asked to identify the prevailing methods implemented by general contractors for selecting safety program elements. The researcher believes that input from experts was desirable for this study because individuals that met the requirements are likely to have a holistic understanding of the construction industry. A holistic understanding of the construction industry was necessary because one objective of the research was to collect data that would represent the behavior and experience of the particular construction project.

In order to apply this concepts presented in safety equilibrium equation 2.2 , we must quantify risk demand and the capacity of safety program.

\subsection{Risk Management Status in the Four Sites}

Risk management status in the four sites differs. Results of the analysis show that Mkpokiti road construction has the greatest safety risk demand of 126 work-hours injury per incident followed by Agbani road with safety risk demand of 112 work-hours injury per incident followed by Rangers avenue road construction with safety risk demand of 105.2 work-hours injury per incident. Desala road has the lowest safety risk demand of 101.4 work-hours injury per incident.

This implies that more risks were encountered in Mkpokiti road construction followed by Agbani road and Rangers avenue road respectively. Desala road encountered less risk.

\subsection{Results of Application of Strategy to Each Site}

Twelve, fourteen, fifteen and seventeen safety program elements were applied in Agbani road, Rangers avenue road, Desala road, and Mkpokiti road construction sites respectively. Results of the analysis shows that safety risk capacity obtained at Agbani road, Rangers avenue road, Desala road, and Mkpokiti road construction sites were 93.23 work-hours injury per incident, 110 work-hours injury per incident, 123.2 work-hours injury per incident, and 132 workhours injury per incident respectively.

The results show that safety program element applied to Mkpokiti road has the greatest ability to mitigate risk while safety program applied to Agbani road has lowest ability. This implies that more safety program element application increases its ability to mitigate risk in the construction site. 


\subsection{Comparisons of Results from the Four Sites}

The graph shown below compared the applications of safety program element in general excavation of topsoil/grading general area activity/process in the four sites of study. The concept used in the graph considers movement towards the horizontal axis as risk environment and that of the vertical axis as risk or accident free. From the graph, one can see that at first the movement is towards the horizontal axis but when safety program element is applied it changes direction towards the vertical axis (risk /accident free). From the results it shows that application of more safety program elements changes direction and drags it down more to the vertical axis.

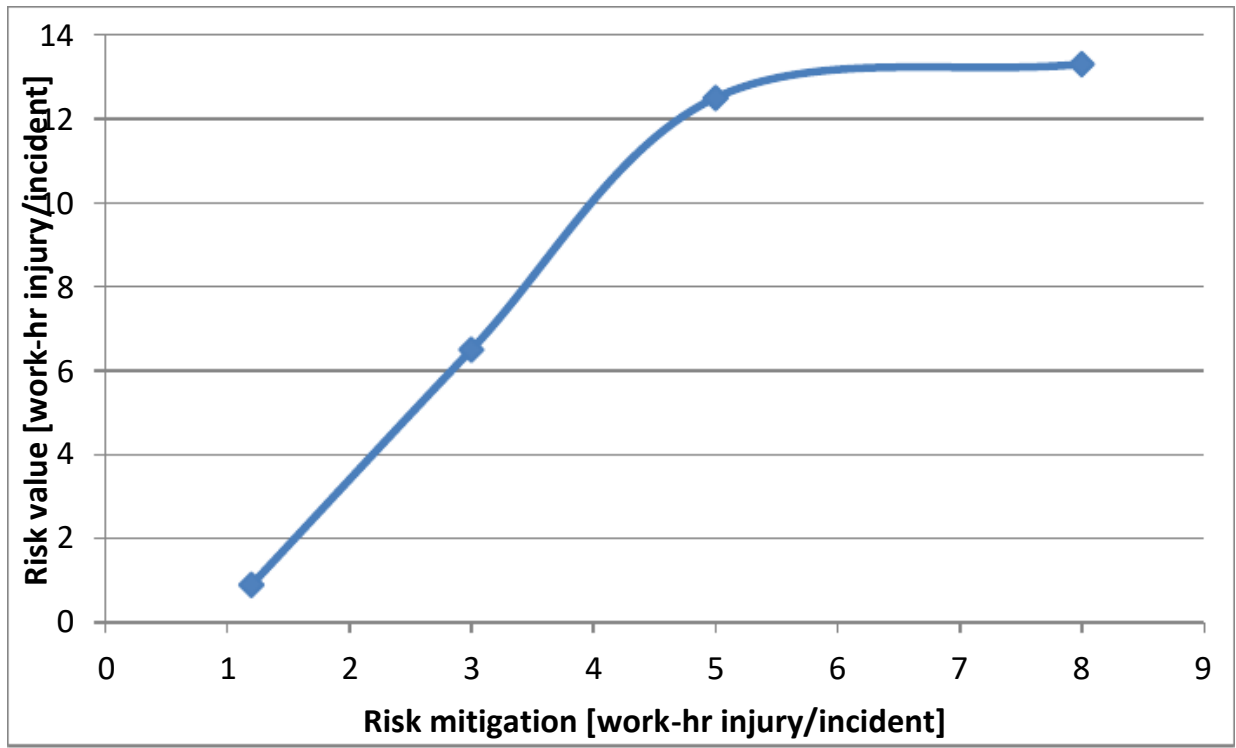

Figure 1 Effect of Safety Risk Mitigation Strategy with Risk Value in Excavation of Topsoil/Grading Process at Agbani road project.

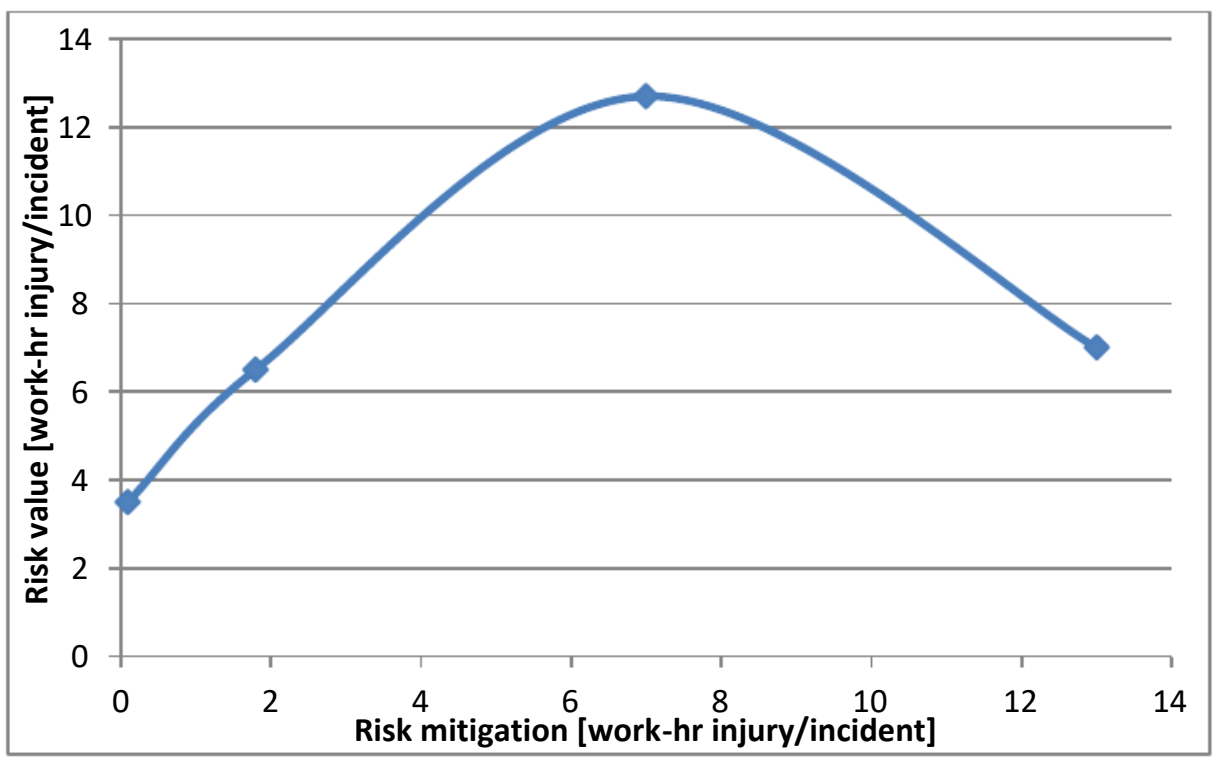

Figure 2 Effect of Safety Risk Mitigation Strategy with Risk Value in Excavation of Topsoil/Grading Process at Ranger's avenue road project. 
Onyeka, F.C. and Agunwamba, J.C.

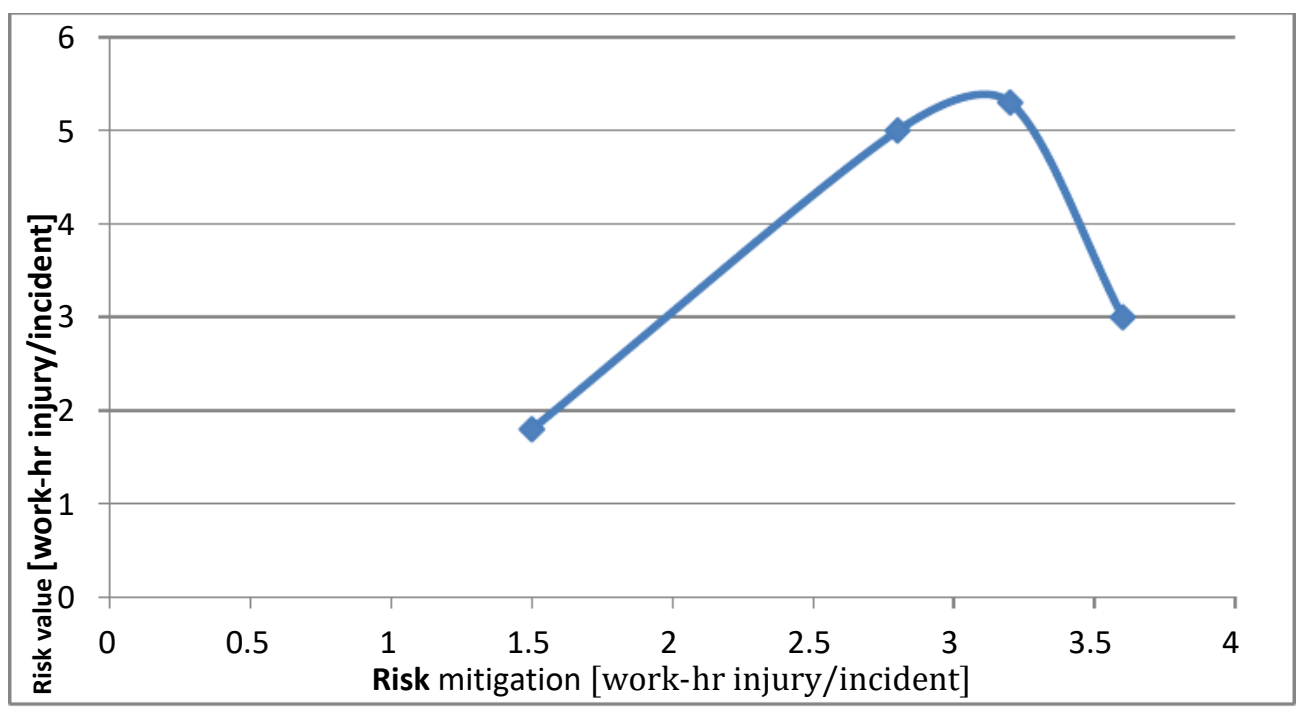

Figure 3 Effect of Safety Risk Mitigation Strategy with Risk Value in Excavation of Topsoil/Grading Process at Desala road project.

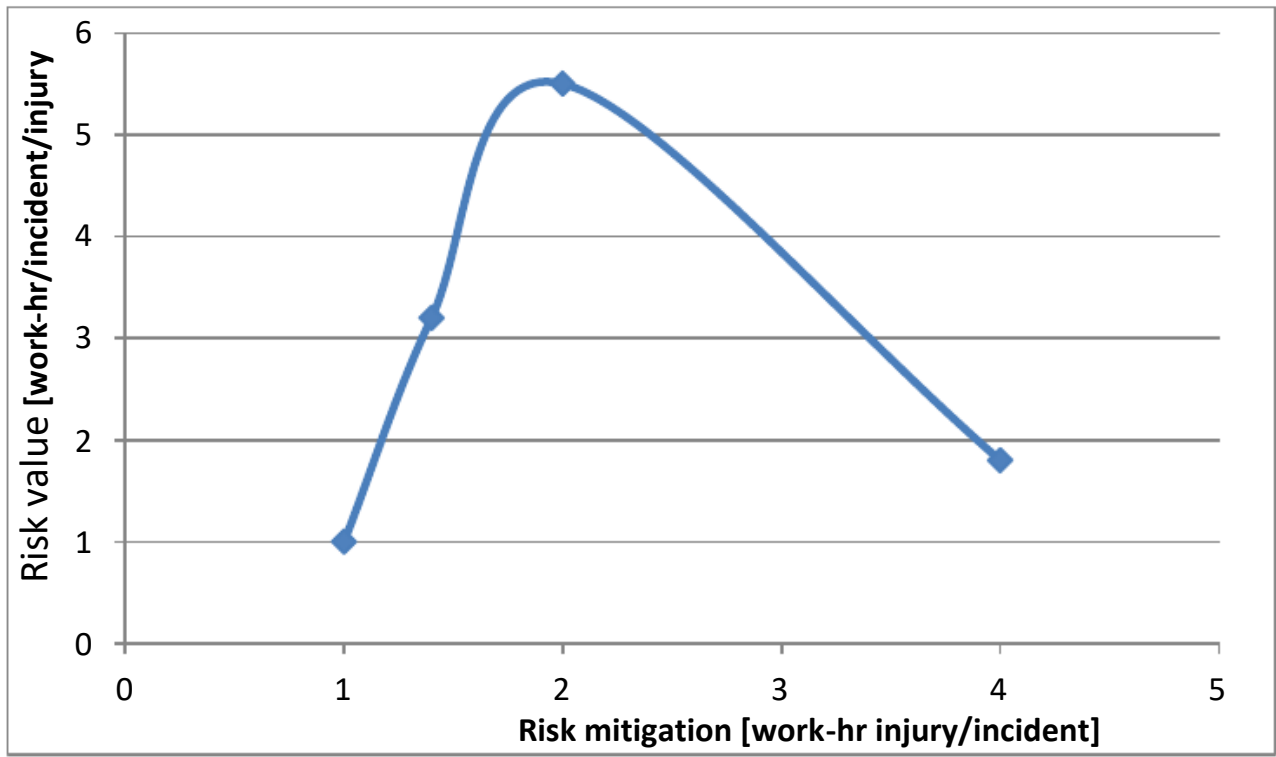

Figure 4 Effect of Safety Risk Mitigation Strategy with Risk Value in Excavation of Topsoil/Grading Process at Mkpokiti road project.

\subsection{Implications of results in risk management}

Agbani road construction having a very high safety risk demands with a very low safety capacity was not guaranteed casualty or accident free despite the inclusion of factor of safety that will achieves accident free. Risk management here is too economical.

Desala and Mkpokiti roads have a very high safety capacity which makes the practice (application) very costly. Here, the risk management is effective but uneconomical.

Ranger's avenue road construction has a moderate application of safety management and a very effective risk management. This was because the variation between safety risk demand and that of safety risk capacity was not much and safety risk capacity is greater than demand safety risk.

In the four sites under study, equation 3.2 satisfied risks or accident free. 


\section{CONCLUSION}

The research was able to show that construction works involved risks and occurrence of unforeseen factors which affect the successful project completion. The level of familiarity and awareness which should constitute the greater percentage amongst the construction practitioners is low. In this work it was observed that application of more safety programs ensure more stability and risk or accident free in the construction project. If risks are improperly assessed and prioritize, time can be wasted in dealing with risk of loses that are not likely to occur. Spending too much time assessing/managing unlikely risks can divert resources that could be used more profitably. Therefore applying more safety program element when stability has been ensured should be waste and should not be encouraged. Unlike events do occur, but if the work is unlikely enough to occur, it may be better to simply retain the risk and deal with the result if the loss does occur. It was also discovered that practical use of this model will help to identify the relative effectiveness of safety program elements for a given process, provide guidance for resource allocation to safety programs, and identify the level of safety intervention required for a given process.

Risk management that is successfully installed in the project gives the chance of gaining a clearer understanding of the targets, duties, contents of services and the feasibility of the project. It provides fundamental information to support decision-making in the target triangular of costs, deadlines and qualities. Best procurement strategy and balancing risk management equilibrium equation will enhance project completion and ensures that the client discovered the value and function for the project in terms of time, cost and quality before or during construction. Therefore it can be concluded that most of the risk prevalent problem in construction industry which led to casualties are preventable if the risks in the construction are well known at the earlier stage of construction.

It is recommended that application of safety mitigation strategy should be done with caution to avoid spending too much money and manpower, and loss which are likely to occur thus, a waste.

\section{REFERENCES}

[1] Abdou, A, Lewis, J and Alzarooni, A, "Modeling Risk for Construction Cost Estimating and Forecasting" Construction Management Proceedings, Vol. 1, 2004, pp 141-52.

[2] Al-Bahar, J.F. \& Crandall, K.C, "Systematic Risk Management Approach for Construction Projects". Journal of Construction Engineering and Management, 116(3), 1990, pp 533-546.

[3] Alvarez, J, Frances A.I.A, Gast, M. and Pieterse, D, “Top 10 Legal Issues in Construction Contracting", Nixon Peabony Attorney At Law, 2002

[4] Barrier, D.S and Paulson Jr, B. C, "Professional Construction Management", McGraw-Hill, 1992

[5] Flanagan, R and Norman, G, "Risk Management and Construction" Blackwell science Ltd, London, 1993

[6] Hallowell, M and Gambatese, J. "A Formal Model for Construction Safety Risk Management" Proceedings of Construction and Building Research (COBRA) Conference, 6-7 September 2007, Georgia Institute of Tech, Atlanta, USA. RICS foundation, 2007

[7] Jannadi, O. A. and S. Almishari, "Risk Assessment in Construction." Journal of Construction Engineering and Management 129(5), 2003, pp 492-500.

[8] Less, S and Halpin, D.W, "Predictive Tool for Estimating Accident Risk" Journal of Construction Engineering and Management 129 (4), 2003, pp 431-436.

[9] Lockyer, K.K and Gordon, V, "Project management and project network techniques" E \& FN Spons, London, 1996 
[10] Meritt, J. W. CSSP, “A method for quantitative risk analysis” Wang Global, 2008

[11] Odeh, A. M and Battaineh, H. T, "Causes of Construction Delay: Traditional Contracts". International Journal of Project Management, Vol 20, 2003, pp 60-73.

[12] Okolie, K.C, "Risk and value management in construction" Unpublished article, Nnamdi Azikiwe University, Awka, 2005

[13] Okwuoma, A.C, "Lecture Note on Risk management technology" Project Management Department Federal University of Technology, Owerri, Unpublished, 2009

[14] Perry, J.G and Hages, R.N., "Risk and its Management in Construction" The Institute of Civil Engineers Proceeding part 1, Vol. 78, 1995, p 499-522.

[15] Pflug, G and Romisch, W, "Modeling, Measuring and Managing Risk" World Scientific, New Jersey and London, 2007

[16] Raftery, J, "Risk Analysis in Project", First UK: E \& FN Spon An imprint of Routledge, London and New York, 1994

[17] Simu, K, "Risk Management in Small Construction Projects" LICENTIATE Thesis of Civil and Environmental Engineering, Division of Architecture and Infrastructure, Lulea University of Technology, 2006

[18] Farah Salwati Ibrahim and Muneera Esa, A Study on Enterprise Risk Management and Organizational Performance: Developer's Perspective, International Journal of Civil Engineering and Technology, 8(10), 2017, pp. 184-196.

[19] Treasury, H.M, "Management of Risk-Principles and Concepts", Her Majesty's Stationary office, London, 2004

[20] R. Prasanna Kumar, Afshan Sheikh and SS.Asadi, A Systematic Approach For Evaluation of Risk Management In Road Construction Projects - A Model Study. International Journal of Civil Engineering and Technology, 8(3), 2017, pp. 888-902.

[21] Dr. C. Mahadeva Murthy and Prof. S.N. Pathi, an Assessment of Risk Management in Banking Sector: A Study with Special Reference to Public and Private Sector Banks in India, Volume 4, Issue 3, September - December 2013, pp. 18-33

[22] Ward, S and Chapman, C, "Transforming Project Risk Management into Project Uncertainty Management", International Journal of Project Management, 2001

[23] An Innovative Process for the Qualification and Evaluation of occupational Risk Management under the OHSAS 18001 Standard. International Journal of Management, 8 (4), 2017, pp. 40 51.

[24] Dr. Shivakumar Deene. An Empirical Examination of Liquidity Risk Management with Special Reference to Vijaya Bank. International Journal of Management, 6(11), 2015, pp. 0118.

[25] SS. Asadi and Vallabhaneni Eswara Rao, an Integrated Approach to a Critical Analysis of Risk Management in Construction Projects. International Journal of Civil Engineering and Technology, 9(3), 2018, pp. 20-28. 